\title{
EL PRINCIPIO DE PRECAUCIÓN EN LA JURISPRUDENCIA INTERNACIONAL
}

\author{
Justo CORTI VARELA*
}

SUMARIO: 1. INTRODUCCIÓN.-2. LA PRUEBA CIENTÍFICA Y EL PRINCIPIO DE PRECAUCIÓN.-2.1. La incorporación de la prueba científica.-2.1.1. La incorporación de la prueba científica en la Corte Internacional de Justicia.-2.1.2. La incorporación de la prueba científica en el Tribunal Internacional del Derecho del Mar--2.1.3. La incorporación de la prueba científica en la Organización Mundial de Comercio.-2.1.4. ¿Pueden las convicciones de un experto hacia el principio de precaución afectar su independencia e imparcialidad?-2.2. La distinción entre elementos fácticos y jurídicos.-3. LA CARGA DE LA PRUEBA Y EL PRINCIPIO DE PRECAUCIÓN.- 4. EL PRINCIPIO DE PRECAUCIÓN Y EL STANDARD OF RE$V I E W .-4.1$. El principio de precaución como atenuante.-4.2. El incumplimiento de obligaciones precautorias internacionales.-5. CONCLUSIONES.

\section{INTRODUCCIÓN}

Siguiendo una definición clásica, podemos decir que el principio de precaución es aquel que afirma:

«Cuando haya peligro de daño grave o irreversible, la falta de certeza científica absoluta no deberá utilizarse como razón para postergar la adopción de medidas eficaces en función de los costos para impedir la degradación del medio ambiente» ${ }^{1}$.

Como puede apreciarse, es un principio dirigido a la toma de decisiones en un contexto de incertidumbre científica. De ahí su inclusión en un gran número de tratados y acuerdos internacionales ${ }^{2}$ que regulan la toma de deci-

* Doctor en Derecho por la Universidad Complutense de Madrid. Profesor Adjunto de Derecho internacional público Universidad CEU San Pablo. Ha sido académico visitante del University College London, investigador post-doctoral del Centre National de la Recherche Scientifique y profesor visitante de la Université Paris X. Correo electrónico: jlcorti@ceu.es.

1 Principio 15 de la Declaración de Río sobre el Medio Ambiente y Desarrollo, 14 de junio de 1992, Naciones Unidas (ONU) Doc. A/CONF.151/26/Rev.1.

2 El primer texto internacional en incluirlo es el correspondiente a la Conferencia Ministerial del Mar del Norte, Bremen, 1 de noviembre de 1984. Los principales instrumentos internacionales que lo incluyen son el Protocolo de Montreal, anejo a la Convención de Viena para la Protección de la Capa de 
siones por parte de los Estados en materias tales como la protección de la salud y vida de personas, animales y plantas, el medioambiente o la seguridad alimentaria. Asimismo, de modo indirecto, el principio de precaución afecta al Derecho comercial internacional ${ }^{3} \mathrm{y}$ al Derecho del $\operatorname{mar}^{4}$ ya que estos se ven en la necesidad de crear excepciones a principios propios, como la libertad de comercio o de pesca en alta mar, para poder garantizar la protección efectiva de los bienes jurídicos antes mencionados.

El principio de precaución, como tal, ha sido estudiado en profundidad por la doctrina internacionalista española ${ }^{5}$ e internacional ${ }^{6}$. No es el objeto

Ozono, 16 de septiembre de 1987; la Convención de Bamako sobre la Prohibición de la importación a África y la fiscalización de los movimientos transfronterizos y el manejo dentro de África de desechos peligrosos, 30 de enero de 1991 [véase art. 4.3.f)]; el Plan de Acción Agenda 21 de la Cumbre de la Tierra de Río (en relación con la protección del medioambiente marino), 14 de junio de 1992; el Acuerdo de la ONU sobre la Aplicación de las Disposiciones de la Convención sobre el Derecho del Mar relativas a la conservación y ordenación de las poblaciones de peces altamente migratorios, Nueva York, 8 de septiembre de 1995, ONU Doc. A/CONF.164/37 (véase art. 6.2); Protocolo de Cartagena sobre Seguridad de la Biotecnología del Convenio sobre la Diversidad Biológica, Montreal, 29 de enero de 2000 (véase preámbulo, arts. 10.6, 11.6 y 11.8); el Convenio de Estocolmo sobre los Contaminantes Orgánicos Persistentes, 23 de mayo de 2001 (véanse arts. 4 y 8.7); y el Acuerdo de París de la Convención Marco sobre el Cambio Climático, 12 de diciembre de 2015, FCCC/CP/2015/L.9/Rev.1. Para un estudio pormenorizado de todos los instrumentos internacionales que lo incluyen véase DE SADELEER, N., Environmental principles: from political slogans to legal rules, Oxford, Oxford University Press, 2002, p. 94. Véase también FreEstone, D. y HeY, E., "Origins and development of the precautionary principle», en Freestone, D. y Hey, E. (eds.), The Precautionary Principle and International Law: The Challenge of Implementation, La Haya, Kluwer Law International, 1996, pp. 3-15, p. 3. Igualmente BIRNIE, P., Boyle, A. y Redgwell, C., International Law and the Environment, Oxford, Oxford University Press, 2009, pp. 154-164. Para un análisis de los antecedentes previos al reconocimiento en los tratados internacionales, véase Trouwbost, A., Evolution and Status of the Precautionary Principle, La Haya, Kluwer Law International, 2002, p. 20.

${ }^{3}$ A falta de una mención expresa en los textos, la jurisprudencia de la Organización Mundial del Comercio (OMC) no reconoce al principio de precaución como tal, pero acepta que durante la evaluación de riesgos del art. 5.1 del Acuerdo sobre la Aplicación de Medidas Sanitarias y Fitosanitarias (Acuerdo MSF) se tenga en cuenta una aproximación de prudencia y precaución, especialmente cuando nos enfrentamos a daños irreversibles o hasta mortales para la vida o la salud de las personas. Véase referencias nota 7. Comentando la jurisprudencia OMC y comparándola con la de la UE, véase CoRTI VARela, J., Organismos Genéticamente Modificados y Riesgos Sanitarios y Medioambientales. Derecho de la Unión Europea y de la Organización Mundial del Comercio, Madrid, Reus, 2010, pp. 199-200. Véase asimismo el art. 5.7 del Acuerdo MSF, de clara inspiración precautoria.

${ }^{4}$ Por ejemplo, el art. 3.2 del Convenio sobre Protección del Medio Marino de la Zona del Mar Báltico, 24 de septiembre de 1992.

5 Rodríguez-Magdaleno, R. I., «El régimen internacional de la pesca de ballenas: entre la conservación y la explotación (a propósito del asunto de la pesca de ballenas en el océano antártico)», Anuario Español de Derecho Internacional, vol. 26, 2010, pp. 143-174; Juste Ruiz, J. y Bou Franch, V. E., «El caso de las plantas de celulosa sobre el río Uruguay: Sentencia de la Corte Internacional de Justicia de 20 de abril 2010», Revista Electrónica de Estudios Internacionales, vol. 21, 2011, núm. 1; OANTA, G. A., «El alcance del principio de precaución en el marco de la Organización mundial del comercio», Anuario da Facultade de Dereito da Universidade da Coruña, vol. 12, 2008, pp. 685-705; y JIMÉNEZ DE Parga Maseda, P., El principio de prevención en el derecho internacional del medio ambiente, Madrid, La Ley-Actualidad, 2001.

6 Trouwhorst, A., «Prevention, Precaution, Logic and Law. The Relationship between the Precautionary Principle and the Preventative Principle in International Law and Associated Questions», Erasmus Law Review, vol. 2, 2009, pp. 105-127; Fitzmaurice, M., Contemporary issues in international environmental law, Cheltenham, Edward Elgar Publishing, 2009, pp. 1-67; GRIMEaud, D., «The precautionary principle in international environmental and trade law», en FAURE, M. y Vos, E. (eds.), 
del presente artículo hacer un estado de la cuestión de esta rica bibliografía. Lo que aquí analizaremos es su tratamiento por la jurisprudencia.

Partimos de la base de que si bien todavía no ha sido reconocido como principio consuetudinario del Derecho internacional ${ }^{7}$, dicho reconocimiento no sería necesario para que pueda alterar la carga de la prueba o influir en el estándar de revisión ${ }^{8}$. Esta capacidad deriva de las dos vertientes del principio: la administrativa, como justificación de decisiones nacionales restrictivas con limitado sustento probatorio; y la propiamente jurisdiccional, como herramienta procesal en los contenciosos internacionales donde la aportación probatoria es escasa o contradictoria. La primera no es controvertida, aunque a veces se anula cuando se contrapone con el principio de soberanía, y será analizada al tratar el estándar de revisión. La segunda, mucho más novedosa, se encuentra en fase de elaboración.

Como herramienta procesal, el principio de precaución puede ayudar a clarificar el tratamiento de la prueba científica compleja en los contenciosos internacionales. Así, la procedimentalización del principio de precaución obliga al juez internacional a repensar la admisibilidad de la prueba científica, un aspecto poco tratado al menos en la Corte Internacional de Justicia (CIJ); y a delimitar los hechos científicos (que pueden quedar bajo la opinión de los

Juridische afbakening van het voorzorgsbeginsel: mogelijkheden en grenzen. Den Haag: Gezondheidsraad, núm. A03/03 2003, pp. 24-26; MARR, S., The precautionary principle in the law of the sea: modern decision making in international law, La Haya, Martinus Nijhoff Publishers, 2003; Trouwborst, A., Evolution and status of the precautionary principle in international law, La Haya, Kluwer Law, 2002; LEBEN, C. (ed.), Le principe de précaution: Aspects de droit international et communautaire, París, Pantheon, 2002; O'Riordan, T., CAmeron, J. y Jordan, A. (eds.), Reinterpreting the Precautionary Principle, Londres, Cameron May, 2001; y Freestone, D. y Hey, E., The precautionary principle and international law: the challenge of implementation, La Haya, Kluwer Law International, 1996.

7 La discusión ha sido particularmente intensa en el ámbito de la OMC donde, a falta de un reconocimiento expreso en los textos y más allá de menciones generales como las comentadas en la nota 3, solo se podría aplicar plenamente en el caso de que fuese posible demostrar que se trata de un principio general del Derecho internacional cosa que, según la jurisprudencia, todavía no habría ocurrido. Véase, a este respecto, Estados Unidos c. Comunidades Europeas, asunto DS26, informe del Órgano de Apelación, 16 de enero de 1998, párr. 124; Estados Unidos c. Comunidades Europeas (en adelante Productos Biotecnológicos), asunto DS291, informe del Grupo Especial, 29 de septiembre de 2006, párrs. 7.73 y 7.89. En el ámbito internacional, solo un laudo de la Corte Permanente de Arbitraje lo ha reconocido abiertamente. Véase el laudo Belgica c. Holanda (en adelante Iron Rhine Railway) de 24 de mayo de 2005, Reports of International Arbitral Awards, vol. XXVII, pp. 35-125, párr. 59. En Derecho europeo sí que ha sido reconocido como principio general: véase asunto C-180/96, ECLI:EU:C:1998:192, párrs. 99-101; y asunto C-157/96, ECLI:EU:C:1998:191, párrs. 62-64. La doctrina internacionalista concuerda en que es un principio del Derecho internacional emergente: véase Freestone, D., "Caution or Precaution: A Rose By Any Other Name...?», Yearbook of International Environmental Law, vol. 10, 2000, núm. 1, pp. 25-32; CAmeron, J., «The Precautionary Principle: core meaning, constitutional framework \& procedures for implementation», en Harding, R. y FISHER, E. (dirs.), Perspectives on the precautionary principle, Sidney, The Federation Press, 1999, p. 30. O que refleja al menos la costumbre internacional: véase Sands, P. y Peel J., Principles of international environmental law, Cambridge, Cambridge University Press, 2012, p. 279; y Cameron, J. y Abouchar, J., "The Status of the Precautionary Principle in International Law», en Freestone, D. y HeY, E., op. cit., nota 6, pp. 29-52, p. 30.

8 Fisher, E., Risk regulation and administrative constitutionalism, Oxford, Bloomsbury Publishing, 2007, pp. 44-46. 
expertos) respecto de las opiniones jurídicas (que corresponden necesariamente al tribunal), otro aspecto no siempre claro.

Clarificar quién incorpora y cómo incorpora la prueba científica, en un contexto de incertidumbre, es esencial en el uso de mecanismos como el de la carga de la prueba. El principio de precaución la altera e incluso puede llegar a invertirla, con lo que la influencia en el procedimiento es trascendental.

En cuanto al fondo, no deja de ser todavía un tema controvertido ya que enfrenta a los jueces y árbitros internacionales ante la obligación de valorar un principio que es, por naturaleza, de dudosa judicialidad ${ }^{9}$. El tribunal internacional deberá decidir qué estándar de revisión va a aplicar sobre las decisiones de los policy makers que, en su mayoría, son autoridades estatales en ejercicio de su soberanía. El juego de la carga de la prueba puede resultar importante para determinar criterios coherentes de revisión, así como otros tales como la razonabilidad o el carácter proporcional de la medida.

Por razones metodológicas, nos circunscribimos a jurisprudencia internacional que sea lo más homogénea posible. Como veremos, la intensidad del principio de soberanía puede tener un efecto importante en la admisibilidad de la prueba, en su valoración y en el juego de la carga. Además el respeto a la soberanía estatal puede disminuir el grado de revisión de las decisiones precautorias y, muy especialmente, las no precautorias. Por tanto, no es lo mismo analizar el uso del principio de precaución en instancias internacionales solo interestatales que en aquellas en donde se dirimen cuestiones entre Estados y particulares (como los tribunales de derechos humanos, los arbitrajes de inversiones o el propio Tribunal Penal Internacional). Por la misma razón se excluyen los tribunales regionales, como el Tribunal de Justicia de la Unión Europea (TJUE), que por efecto de la transferencia de soberanía ejercida en los tratados constitutivos, no aplica el principio de soberanía estatal en toda su amplitud sino más bien el de primacía del Derecho europeo sobre el nacional e incluso el internacional ${ }^{10}$.

Por tanto, se tratará aquella jurisprudencia internacional interestatal relacionada con problemas de prueba científica en un contexto de incer-

9 El principio de precaución es esencialmente una guía para el policy maker en la toma de decisiones de gestión de riesgos. Su judicialización es, por tanto, compleja tanto a nivel interno como internacional ya que implica la revisión de decisiones esencialmente políticas adoptadas, normalmente, en contextos donde hay un amplio margen de discrecionalidad. Volveremos sobre este aspecto en la sección 4 del presente artículo. Al respecto, véase FISHER, E., «Is the precautionary principle justiciable?», Journal of Environmental Law, vol. 13, 2001, núm. 3, pp. 315-334. Desde una perspectiva más general, sobre la judicialidad de los casos científicos complejos, Japón en Southern Bluefin Tuna Cases (New Zealand v. Japan; Australia v. Japan), Provisional Measures (en adelante Atún de aleta azul), asuntos 3 y 4, argumentó que "Questions of scientific judgment [...] are not justiciable» [véase p. 40.a)]. El Tribunal Internacional del Derecho del Mar (TIDM) no aceptó esta interpretación.

10 Además este Tribunal muy rara vez resuelve una disputa entre Estados. Solo existe dicha posibilidad en el recurso por incumplimiento (art. 159 del Tratado de Funcionamiento de la Unión Europea -TFUE-) siempre y cuando la etapa pre-contenciosa no la haya iniciado la Comisión (art. 158 TFUE). Véase Mangas Martín A. y LiÑán Nogueras D. J., Instituciones y Derecho de la Unión Europea, 9. a ed., Tecnos, 2016, pp. 461-490. 
tidumbre que es, esencialmente, el campo donde se aplica el principio de precaución: la de la CIJ ${ }^{11}$, la del Órgano de Solución de Diferencias (OSD) de la Organización Mundial del Comercio (OMC) ${ }^{12}$ y la del Tribunal International del Derecho del Mar (TIDM) ${ }^{13}$. Si bien hay otras instancias internacionales interestatales donde se pueden encontrar ejemplos de la aplicación del principio, principalmente en tribunales arbitrales ad hoc ${ }^{14}$, la falta de homogeneidad en su uso así como la falta de un número de sentencias lo suficientemente importante para percibir un desarrollo jurisprudencial nos hacen decantarnos por circunscribir el estudio a las tres instancias antes mencionadas.

Primeramente analizaremos cómo el principio de precaución influye en el tratamiento que recibe la prueba, científica e incierta, en los contenciosos internacionales. La forma en que se introduce la prueba (solo de parte o también con medios probatorios propios del tribunal) puede alterar su valoración, en especial, para dilucidar si hay o no incertidumbre. Resulta importante analizar los mecanismos para aislar los elementos fácticos de los jurídicos, muchas veces fuertemente interconectados cuando se trata de prueba científica compleja, para impedir que el poder de decisión se traslade de los jueces a los expertos.

En segundo lugar, especialmente si se adopta una etapa probatoria esencialmente contenciosa, destacaremos el impacto sobre la carga de la prueba. La falta de aportación de prueba suficiente del principio de precaución por

11 Request for an Examination of the Situation in Accordance with Paragraph 63 of the Court's Judgment of 20 December 1974 in Nuclear Tests (New Zealand v. France) (en adelante Pruebas Nucleares II), 22 de septiembre de 1995, ICJ Reports 1995, p. 288; Gabčíkovo-Nagymaros Project (Hungary v. Slovakia) (en adelante Gabčíkovo), 25 de septiembre de 1997, ICJ Reports 1997, p. 7; Pulp Mills on the River Uruguay (Argentina v. Uruguay) (en adelante Plantas de Celulosa), 20 de abril de 2010, ICJ Reports 1997, p. 14; Whaling in the Antarctic (Australia v. Japan: New Zealand intervening) (en adelante Ballenas), 31 de marzo de 2014, ICJ Reports 2014, p. 226. En el asunto Ballenas, si bien el principio de precaución fue mencionado y analizado en un voto particular (véase voto particular del Juez Cançado Trindade, párrs. 70-71), no se llegó a aplicar ya que Japón no fue capaz de demostrar que su programa estaba sustentado en argumentos científicos.

12 Estados Unidos c. Comunidades Europeas (en adelante Hormonas), asunto DS26, informe del Grupo Especial, 18 de agosto de 1997 e informe del Órgano de Apelación, 16 de enero de 1998; India, Malasia, Pakistán, Tailandia c. Estados Unidos (en adelante Camarones), asunto DS58, informe del Grupo Especial, 15 de mayo de 1998 e informe del Órgano de Apelación, 12 de octubre de 1998; Estados Unidos c. Japón (en adelante Productos agrícolas), asunto DS76, informe del Grupo Especial, 27 de octubre de 1998 e informe del Órgano de Apelación, 22 de febrero de 1999; Canadá c. Comunidades Europeas (en adelante Amianto), asunto DS135, informe del Grupo Especial, 18 de septiembre de 2000 e informe del Órgano de Apelación, 12 de marzo de 2001; Productos Biotecnológicos (op. cit., nota 7); y Comunidades Europeas c. Estados Unidos (en adelante Hormonas II) asunto DS320, informe del Grupo Especial, 31 de marzo de 2008 e informe del Órgano de Apelación, 16 de octubre de 2008.

${ }_{13}$ Atún de aleta azul, op. cit., nota 9; The MOX Plant Case (Ireland v. United Kingdom), Provisional Measures (en adelante Planta MOX), asunto 10, decisión de 3 de diciembre de 2001; y Case concerning Land Reclamation by Singapore in and around the Straits of Johor (Malaysia v. Singapore), Provisional Measures (en adelante Malasia c. Singapur), asunto 12, decisión de 8 de octubre de 2003.

14 Por ejemplo, el antes mencionado laudo Iron Rhine Railway, op. cit., nota 7, o en el ámbito del arbitraje de inversiones, en Marion Unglaube y otro c. República de Costa Rica, casos CIADI núms. ARB/08/1 y ARB/09/20, laudo de 12 de junio 2008, párr. 130. 
JUSTO CORTI VARELA

quien tiene la carga puede conllevar la finalización del proceso incluso sin llegar a analizarse el fondo, pero, ¿cómo valorar esa falta en un contexto donde, per se, hay incertidumbre científica? Por ello estudiaremos si, en tales casos, el principio de precaución puede alterar o incluso llegar a revertir dicha carga.

En tercer término se tratará el principio de precaución no en su faceta probatoria sino de fondo. Primero, como parámetro de revisión de las decisiones estatales precautorias que puedan considerarse contrarias a principios del Derecho internacional. Aquí el principio de precaución refuerza la acción de los Estados justificando excepciones (muchas de estas adoptadas en un contexto de defensa de la soberanía sanitaria, alimentaria o medioambiental) que carecen de prueba científica completa. Segundo, estudiaremos cómo ha interpretado y aplicado la jurisprudencia internacional la situación contraria, es decir, cuando los Estados parecen violar el principio de precaución proveniente de textos internacionales. Aquí hay una oposición entre precaución y soberanía, por lo que la respuesta de la jurisprudencia es más tibia y se encamina a la resolución del conflicto más por medio de la cooperación que a través de una condena clara al Estado infractor.

\section{LA PRUEBA CIENTÍFICA Y EL PRINCIPIO DE PRECAUCIÓN}

Los tribunales internacionales deben resolver los casos que se les presentan «de acuerdo con el Derecho internacional» ${ }^{15}$, pero los hechos resultan esenciales para aplicar el Derecho al caso concreto ${ }^{16}$. El Derecho es parte del dominio del conocimiento de los jueces (jura novit curia) pero los hechos están en la periferia del control judicial y requieren de un procedimiento (probatorio) para su judicialización ${ }^{17}$. Este puede, por ello, ser especialmente complejo cuando por la naturaleza de la prueba, por ejemplo, su carácter técnico o científico, se aleja mucho del área de conocimiento de los jueces ${ }^{18}$. En tales supuestos es necesario que expertos colaboren con los jueces para una correcta incorporación en el procedimiento ${ }^{19}$ y una posterior adecuada

15 Por ejemplo, art. 38(I) del Estatuto de la CIJ.

16 De lo contrario, sentencias y laudos serían una mera abstracción: véase MBEngue, M. M., «Scientific Fact-finding at the International Court of Justice: An Appraisal in the Aftermath of the Whaling Case», Leiden Journal of International Law, vol. 29, 2016, pp. 529-550, p. 531.

17 Foster, C. E., Science and the precautionary principle in international courts and tribunals: expert evidence, burden of proof and finality, Cambridge, Cambridge University Press, 2011, p. 5.

18 Álvarez, J. E., «Are International Judges Afraid of Science?: A Comment on Mbengue», Loyola of Los Angeles International and Comparative Law Review, vol. 34, 2012, pp. 12-36.

19 Sobre la siempre compleja relación entre expertos y Derecho internacional, desde una perspectiva general, véase Ríos RodríGuez, J., L'expert en droit international, París, Pedone, 2010 (con prefacio de Yves Daudet e introducción de José Manuel Sobrino Heredia). Para una perspectiva más centrada en la función judicial, véase RUIZ FABRI, H. y GRADONI, L., La circulation des concepts juridiques: le droit international de l'environnement. Entre modialisation et fragmentation, París, Société de législation comparée, UMR de droit comparé de Paris, vol. 16, 2009, pp. 267-304. 
valoración ${ }^{20}$, sin que por ello se deba eliminar la separación tradicional entre hechos y Derecho ${ }^{21}$.

Uno de los elementos que distingue a la prueba científica del resto es que enuncia probabilidades en vez de verdades ${ }^{22}$. Además, el contenido y la calidad de la prueba científica no son inmutables sino que van variando con el tiempo. Posiciones minoritarias de hoy pueden ser mayoritarias en el futuro, lo que abre la puerta a continuas reevaluaciones y pone en duda el principio de cosa juzgada ${ }^{23}$. Incluso recientemente la ciencia se ha convertido en un fenómeno social. Posiciones que en la comunidad científica serían incuestionables pueden verse debilitadas ante la desconfianza social, que reclama la democratización de las decisiones tomadas en base a pruebas científicas ${ }^{24}$. La percepción del riesgo, especialmente en caso de incertidumbre, afecta el modo en que los políticos toman decisiones y los jueces valoran la calidad de los resultados científicos que le sirvieron de base ${ }^{25}$. Como dijo la CIJ en el asunto de las Plantas de Celulosa la prueba científica es una categoría especial que requiere un tratamiento por separado ${ }^{26}$.

\subsection{La incorporación de la prueba científica}

La prueba científica se introduce en los procedimientos internacionales de la mano de los expertos. Este tipo de prueba puede producirse a propuesta de parte o por impulso del propio tribunal. Si bien recientemente los tribunales internacionales parecen estar más abiertos a esta última opción ${ }^{27}$, la tradición anglosajona que todavía impera en los procedimientos conduce a cierta pasividad ${ }^{28}$ en la admisión de pruebas, dejando por tanto en las partes

${ }^{20}$ La prueba científica puede llegar a ser determinante. Como dijo el Órgano de Apelación en Hormonas II: "Los expertos nombrados por un grupo especial pueden influir de forma significativa en el proceso de adopción de decisiones. Si un grupo especial no se asegura de que se respeten los requisitos de independencia e imparcialidad en sus consultas con los expertos, se puede poner en peligro la equidad del procedimiento y la imparcialidad de la toma de decisiones», párr. 480.

${ }^{21}$ La separación entre los hechos y el Derecho es particularmente importante ante órganos de apelación, como el de la OMC, ya que no pueden valorar más que el Derecho y la interpretación realizada por el Panel: véase art. 17.6 del Entendimiento Solución de Diferencias (ESD) de la OMC.

22 D’Aspremont, J. y Mbengue, M. M., «Strategies of Engagement with Scientific Fact-finding in International Adjudication», Journal of International Dispute Settlement, vol. 5, 2014, núm. 2, pp. 240272, p. 246.

${ }^{23}$ Foster, C. E., op. cit., nota 17, dedica un capítulo completo a este aspecto: «Reassessment proceedings and res judicata», pp. 318 y ss.

${ }^{24}$ Howse, R., «Democracy, science, and free trade: Risk regulation on trial at the World Trade Organization», Michigan Law Review, vol. 98, 2000, núm. 7, pp. 2329-2357.

25 JASANOFF, S., "What judges should know about the sociology of science», Jurimetrics, vol. 32, 1992, núm. 3, pp. 345-359, p. 349.

26 Plantas de Celulosa, op. cit., nota 11, párr. 109. Coincidentemente votos particulares del Juez Cançado Trindade (p. 191) y del Juez Yusuf (p. 219). Esta misma opinión se encuentra también en la doctrina. Por ejemplo, Riddell, A. y Plant, B., Evidence before the International Court of Justice, Londres, British Institute of International and Comparative Law, 2009, p. 344.

27 Sobre el cambio de paradigma: véase Foster, C. E., op. cit., nota 17, p. 23.

28 Devaney, J., Fact finding before de International Court of Justice, Cambridge, Cambridge University Press, 2016, habla de «reactive approach» en general respecto a la prueba, entre otras razones, 
la iniciativa de su producción ${ }^{29}$. En la práctica los tribunales internacionales desarrollan posiciones mixtas. Por un lado la CIJ, y en menor medida el TIDM, siguen un criterio tradicional fundado en la contrastación de la prueba de parte (cross-examination). Por el otro encontramos una posición más moderna encarnada por el OSD de la OMC, donde hay una aproximación flexible e integral de la prueba científica.

\subsubsection{La incorporación de la prueba científica en la Corte Internacional de Justicia}

La falta de reglas específicas sobre la admisibilidad ${ }^{30}$ y la aplicación del principio de liberté de la preuve hace que la prueba de parte se introduzca en los procedimientos sin ningún tipo de limitación ${ }^{31}$. El principio de soberanía sería la principal causa de esta laxitud y se explicaría, según James Gerard Devaney ${ }^{32}$, por el hecho que al fin y al cabo la jurisdicción de la CIJ es consensuada. Una actitud muy rígida por parte de la Corte podría llevar a las partes a buscar otros mecanismos de resolución de controversias. La falta de una norma expresa en el Estatuto o el Reglamento para compeler a las partes a que ellas produzcan una prueba, o cómo hacerlo, tampoco contribuye ${ }^{33}$. Por ejemplo, en el asunto de las Plantas de Celulosa, las partes aportaron la prueba científica esencialmente a través de expertos que actuaban como advisors ${ }^{34}$ (art. 43 del Reglamento) lo que impidió someterlos a un proceso

por el principio de soberanía que impera en los procedimientos inter-estatales. Véase p. 30. Sobre la pasividad véase ScHweBEL, S. B., "Three cases of fact-finding by the International Court of Justice in International law», en LiLlich, R. B. (ed.), Fact-Finding before International Tribunals, Irvington-onHudson, Transnational, 1991, p. 3.

29 Así, en el sistema anglosajón la regla es que la producción de la prueba es a propuesta de parte y una de las labores del juez constituye, precisamente, en contrastar (e incluso enfrentar) una prueba con otra para tratar de dilucidar la verdad. Véase RidDELl, A. y PlANT, B., op. cit., nota 26, p. 312. En el TJUE, en cambio, se siguen esquemas más continentales. Así, el juez de Luxemburgo mantiene la tradición que impera en la mayoría de los Estados miembros buscando la verité juridique de modo activo. Los testimonios periciales de oficio, a pesar de estar permitidos y regulados en el reglamento de procedimiento, son, sin embargo, poco frecuentes, primando la valoración de los testimonios periciales de parte según el principio contradictorio. Véase BRossET, E., «L'Expert, l'expertise et le juge de l'Union Européenne», en Truilhé-Marengo, E. (dir.), La relation juge-expert dans le contentieux sanitaires et environnementaux, París, CERIC - La documentation Française, 2011, pp. 247-280.

30 Brown, C., A Common Law of International Adjudication, Oxford, Oxford University Press, 2007, p. 90. Véase, además, Brower, C. N., «Evidence before International tribunals: The need of some standard rules», The International Lawyer, vol. 28, 1994, núm. 47, pp. 47-57.

31 Solo hay dos excepciones: la prueba fruto de negociaciones entre las partes y la obtenida de forma ilegal. Véase ReISMAN, W. M. y FreEdman, E. E., "Plaintiff's dilemma: Illegally obtained evidence and admissibility in International adjudication», American Journal of International Law, vol. 76, 1982, pp. 737-753, p. 739.

32 Devaney, J., op. cit., nota 28, p. 38, y Schwebel, S. B., op. cit., nota 28, p. 4.

33 Teitelbaum, R., «Recent Fact-Finding Developments at the International Court of Justice», The Law \& Practice of International Courts and Tribunals, vol. 6, 2007, núm. 1, pp. 119-158, p. 129. Resaltando la falta de reglas sobre cómo realizar el cross-examination, MBEngue, M. M., op. cit., nota 16, p. 544.

34 Sobre el rol de los expertos como advisors (Plantas de Celulosa, op. cit., nota 11) o advocates presenting the science (Gabčíkovo, op. cit., nota 11, Malasia c. Singapur, op. cit., nota 13): véase FosTER, C. E., op. cit., nota 17, p. 88. 
de cross-examination o re-examination. En cambio, en el más reciente asunto sobre las Ballenas, los expertos acudieron como testigos (art. 63 del Reglamento), fueron examinados por su parte, por la contraparte y preguntados por los jueces ${ }^{35}$.

La CIJ hace un uso limitado de los expertos de oficio, en comparación con otros tribunales internacionales más especializados. Esto se debería al carácter generalista de su jurisdicción ${ }^{36}$. En muy contadas ocasiones ${ }^{37}$ la CIJ ha utilizado la facultad que le otorga el art. 50 de su Estatuto para:

«Comisionar a cualquier individuo, entidad, negociado, comisión u otro organismo que ella escoja, para que haga una investigación o emita un dictamen pericial».

Tampoco ha utilizado intensamente ${ }^{38}$ el art. 34.2 que le permite:

«Solicitar de organizaciones internacionales públicas información relativa a casos que se litiguen ante la Corte, y recibirá la información que dichas organizaciones envíen a iniciativa propia».

En la CIJ estas aportaciones no estarían sujetas al cross-examination y, por tanto, podrían surgir problemas en relación con el respeto al debido proceso ${ }^{39}$.

Ante la indiscutible necesidad de los jueces de asesorarse, aunque muy criticada ${ }^{40}$, existe una costumbre arraigada de informarse sobre las cuestiones técnicas a través de los llamados experts fantômes ${ }^{41}$. Sin embargo, ni su iden-

35 Ballenas, op. cit., nota 11, párr. 20, y MBENGUe, M. M., op. cit., nota 16, p. 538.

36 Ríos Rodríguez, J., "Expert et juge international», en Truilhé-Marengo, E. (dir.), op. cit., nota 29, pp. 117-134, p. 122. Guilbert Guillaume afirmó: «Le juge inter étatique n'est pas un juge Pénal. [...] Il lui suffit d'arriver à [...] une certitude raisonnable que d'ailleurs est probablement différentes selon les domaines»: véase GuILlaume, G., "Commentaire au rapport de Raphaël Rivier relatif à la preuve devant les juridictions inter étatiques à vocation universelle (CIJ et TIDM)», en RUIZ FABRI, H. y SorEL, J. M. (dirs.), La preuve devant les juridictions internationales, París, Pedone, 2007, p. 55.

37 Curiosamente sí que lo utilizó en el primer caso de la CIJ, el del Canal de Corfú: Corfu Channel (United Kingdom of Great Britain and Northern Ireland v. Albania), 9 de abril de 1948, ICJ Reports, p. 4, p. 21. Otro ejemplo es el caso del Golfo de Maine: Delimitation of the Maritime Boundary in the Gulf of Maine Area (Canada/United States of America), 12 de octubre de 1984, ICJ Reports, p. 246, apdo. II(3). En cambio en el caso Gabčíkovo (op. cit., nota 11) no se consideró necesario (p. 42). En contra, opinión del Juez Weeramantry, p. 118. En apoyo a estas críticas, véase Thompson, L. G. J., «The ECJ and the case concerning the Gabcikovo-Nagymaros Project: The Implications for International Watercourses Law and International Environmental Law», CEPMLP Annual Review, 1999. Tampoco lo utilizó en el asunto sobre las Plantas de Celulosa, op. cit., nota 11, donde la CIJ decidió principalmente sopesar y valorar (p. 72). Véase asimismo comentarios de votos particulares de los Jueces Al Khasawneh y Simma, p. 111.

38 Pierre-Marie Dupuy cita solo tres asuntos (Aerial Incident of 27 July 1955, ICAO Council Case y el Genocidio en Bosnia) en donde se requirieron informes al Consejo de la Organización Internacional de Aviación Civil (en los dos primeros) y en el último a la Secretaria General de ONU: véase DupuY, P. M., «Article 34», en Zimmermann, A., Oellers-Frahm K., Tomuschat, Ch. y Tams, C. J. (eds.), The Statute of the International Court of Justice: A Commentary, Oxford, Oxford University Press, 2006, p. 551.

39 Mbengue, M. M., op. cit., nota 16, p. 545.

40 Incluso son mencionados en el voto particular de los Jueces Al-Khasawneh y Simma en Plantas de Celulosa, op. cit., nota 11, párr. 14 .

41 JENNINGS, R., "International lawyers and the progressive development of international law», en MaKarCZK, J. (ed.), Theory of international law at threshold of the 21st century: essays in honour of Krzysztof Skubiszewski, Leiden, Brill, 1996, p. 416. 
tidad ni opiniones quedan formalmente reflejadas en el caso, lo que despierta serias dudas sobre si:

"Such a practice would deprive the Court of the above-mentioned advantages of transparency, openness, procedural fairness, and the ability for the Parties to comment upon or otherwise assist the Court in understanding the evidence before it» ${ }^{42}$.

En supuestos donde la aportación de información por las partes es deficiente la actitud de la CIJ es la de quitar importancia al contenido fáctico del asunto, hacer una división tajante entre hechos y derecho, y centrar la resolución del conflicto en complicados análisis de «legal rationality to shield itself form sicentific controversies» ${ }^{43}$. Un ejemplo de esta actitud sería el asunto Legality of Threat or Use of Nuclear Weapons donde la CIJ consideró que no era necesario:

«[to] study various types of nuclear weapons and to evaluate highly complex and controversial technological, strategic and scientific information ${ }^{44}$.

Como veremos en la sección 2.3 esta solución no siempre es posible ya que en la mayoría de los supuestos donde hay incertidumbre científica los elementos fácticos y jurídicos están intrínsecamente interrelacionados.

\subsubsection{La incorporación de la prueba científica en el Tribunal Internacional del Derecho del Mar}

El art. 289 de la Convención de Naciones Unidas sobre el Derecho del Mar permite al TIDM nombrar expertos para clarificar cuestiones científicas o técnicas, sea a propuesta de parte, sea de oficio. Estos expertos serán, preferentemente, elegidos de las listas creadas por el art. 2 del Anexo VIII de la citada convención que son, a su vez, nombrados por organizaciones internacionales especializadas ${ }^{45}$ en base a las propuestas de los Estados miembros. Por su parte el art. 72 del reglamento del TIDM permite a las partes hacer intervenir a un experto como medio de prueba. Estos expertos, a diferencia de los del art. 289, no pueden participar en las audiencias ni en las deliberaciones. Es decir, las aportaciones de los expertos del art. 72 son meros testimonios o expert witness.

42 Plantas de Celulosa, op. cit., nota 11, voto particular de los Jueces Al-Khasawneh y Simma, p. 114. Véase, además, Zimmermann, A., Oellers-Frahm K., Tomuschat, Ch. y Tams C. J. (eds.), The Statute of the International Court of Justice: A Commentary, Oxford, Oxford University Press, 2006, p. 1118 (comentando el art. 50). Para un análisis del propio caso, véase SwEENEY-SAMUELSON, C., «Adjudicating conflicts over resources: The ICJ's treatment of technical evidence in the Pulp Mills case», Goettingen Journal of International Law, vol. 2, 2010, p. 454.

43 FrancK, T. M., "Fact-finding in the ICJ», en LILLICH, R. B. (ed.), Fact-Finding before International Tribunals, Irvington-on-Hudson, Transnational, 1991, p. 3, p. 28.

44 Legality of the Use by a State of Nuclear Weapons in Armed Conflict, 1 de febrero de 1995, ICJ Reports, p. 3, párr. 15.

45 La lista de expertos en pesca es propuesta por la Organización de Naciones Unidas para la Alimentación y la Agricultura, la de protección y preservación del medio marino por el Programa de Naciones Unidas para el Medioambiente, la relativa a la investigación marina por la Comisión Oceanográfica Intergubernamental y la concerniente a la navegación y contaminación de buques por la Organización Marítima Internacional. 
Si bien ambas posibilidades están disponibles, en la práctica el TIDM sigue el mismo criterio de la CIJ al dejar el peso de la incorporación de la prueba científica en manos de los expertos de partes. El TIDM, asimismo e inspirándose en el common law, considera las aportaciones de los expertos como un testimonio y al experto un testigo-experto ${ }^{46}$. Incluso el reglamento del TIDM carece de un mecanismo específico para valorar las aportaciones de los expertos más allá de la cross-examination ${ }^{47}$, lo que reduce la participación de los jueces en el proceso de incorporación de la prueba científica. La pasividad ha quedado demostrada cuando en el asunto Atún de aleta azul las partes invitaron a los jueces a hacer preguntas a los expertos y estos declinaron la invitación con el argumento de que la urgencia en que debían adoptarse las medidas cautelares impedía llevar a cabo dicha sugerencia ${ }^{48}$. Según Emmanuelle Jouannet, la razón de esta actitud sería que los tribunales interestatales no quieren arribar a verdades científicas sino meramente jurídicas ${ }^{49}$. Para llegar a estas últimas solo interesa lo que las partes han probado o dejado de probar siguiendo el proceso contradictorio por más que la verdad científica vaya por otros derroteros ${ }^{50}$.

\subsubsection{La incorporación de la prueba científica en la Organización Mundial de Comercio}

A diferencia de la CIJ y del TIDM los Grupos Especiales de la OMC han utilizado intensamente ${ }^{51}$ las facultades que les otorgan el art. 13 del Entendimiento Solución de Diferencias (ESD) para:

«Recabar información y asesoramiento técnico de cualquier persona o entidad que estime conveniente» [...] «y consultar a expertos para obtener su opinión sobre determinados aspectos de la cuestión».

Esta intensa capacidad investigativa ${ }^{52}$, de carácter global ${ }^{53}$, en principio ilimitada ${ }^{54}$, hace que los expertos de parte sean recibidos con cierta reticencia, considerándose que no tienen tanta imparcialidad como los que propone

46 NiyungeKo, G., La preuve devant les juridictions internationales, Bruselas, Bruylant, 2005, p. 154.

47 Gambardella, S., "Les enjeux de l'expertise dans les contentieux environnementaux devant le Tribunal International du Droit de la Mer», en Truilhé-Marengo, E. (dir.), op. cit., nota 29, p. 145.

48 Atún de aleta azul, op. cit., nota 13, párr. 80.

49 Jounnnet, E. «La preuve comme reflet des évolutions majeures de la société internationale», en Ruiz Fabri, H. y Sorel, J. M., La preuve devant les juridictions internationales, París, Pedone, 2007, p. 240 .

50 Gambardella, S., op. cit., nota 47, p. 157. Sobre el principio contradictorio y la prueba pericial: véase JouAnNET, E., "Remarques conclusives sur le principe du contradictoire devant les juridictions internationales», en RUIZ FABRI, H. y SOREL, J. M. (dirs), op. cit., nota 36, p. 182.

51 Christoforou, T., "WTO Panels in Face of Scientific Uncertainty», en WeIss, F. (ed.), Improving WTO Dispute Settlement Procedures: Issues and Lessons from the Practice of Other International Courts and Tribunals, Londres, Cameron May, 2000, p. 258.

52 Productos Agrícolas, op. cit., nota 12, informe del Órgano de Apelación, párr. 129.

53 Camarones, op. cit., nota 12, informe del Órgano de Apelación, párr. 104.

54 Brasil c. Canadá, medidas que afectan a la exportación de aeronaves civiles, asunto DS70, informe del Órgano de Apelación, 2 de agosto de 1999, párr. 185. 
el propio Grupo Especial ${ }^{55}$. Incluso, y a diferencia de la CIJ, la OMC no busca provocar el enfrentamiento de expertos de parte, resaltando sus contradicciones, sino más bien todo lo contrario, considerando que estos choques poco aportan a la resolución del caso ${ }^{56}$. La prueba pericial de oficio consta de un procedimiento que incluye la selección de los expertos, la formulación de las preguntas y la celebración de entrevistas ${ }^{57}$ e incluye la posibilidad de que las partes comenten los informes en la fase oral, con lo que habría una suerte de cross-examination sobre los peritos de oficio ${ }^{58}$. Una de las principales funciones de este asesoramiento es, precisamente, dar a los miembros del Grupo Especial elementos para poder valorar las pruebas científicas aportadas por las partes ${ }^{59}$.

Una particularidad de la OMC es la posibilidad de nominar expertos a título individual o a grupos de expertos. Como destaca Eve Truilhé-Marengo los grupos especiales han evitado utilizar la segunda opción, probablemente porque una aportación de un grupo, fruto del consenso, sería mucho más difícil de matizar ${ }^{60}$. Así, en Hormonas, Amianto, Productos Biotecnológicos y en Hormonas II los expertos nominados lo fueron a título individual a pesar que en los dos primeros las Comunidades Europeas (CE) habían solicitado la constitución de grupos. Sin embargo, esta reticencia a la colegialidad se ve compensada por la presencia de grupos de expertos permanentes, tales como el creado por el art. 11.2 del Acuerdo MSF, que ha sido consultado en todos (excepto uno) los casos relativos a medidas sanitarias y fitosani$\operatorname{tarias}^{61}$.

Otra especificidad de la prueba científica en los contenciosos OMC es la amplitud con la que se admite aportaciones de terceros interesados, los amici curie $^{62}$, incluso durante la etapa de la apelación cuando, formalmente, el Órgano de Apelación solo puede valorar el derecho ${ }^{63}$. Sin embargo, las me-

55 Paunelyn, J., "The use of experts in WTO dispute settlement», International and Comparative Law Quarterly, vol. 51, 2002, núm. 2, pp. 325-364, p. 334.

56 Marceau, G. y Hawkins J. K., "Experts in WTO Dispute Settlement», Journal of International Dispute Settlement, vol. 3, 2012, núm. 3, pp. 493-507, p. 505.

57 Productos Biotecnológicos, op. cit., nota 12, párr. 7.20. De modo similar en Amianto y Hormonas (op. cit., nota 12)

58 Mbengue, M. M., op. cit., nota 16, p. 546.

59 Pauwelyn, J., op. cit., nota 55, p. 329.

60 Truilhé-Marengo, E., «La science, l'expert et le juge de l'OMC. Modele ou contre-modele?», en Truilhé-Marengo, E. (dir.), op. cit., nota 29, p. 163.

61 Marceau, G. y Hawkins, J. K., op. cit., nota 56, p. 501. Un grupo similar se encuentra en el art. 14.2 del Acuerdo sobre Obstáculos Técnicos al Comercio de la OMC.

62 Steger, D. P., "Amicus Curiae: Participant or Friend? The WTO and NAFTA Experience», en vON Bogdandy, A., Mavroidis, P. C. y MÉNy, Y. (eds.), European Integration and International Coordination: Studies in Honour of Claus-Dieter Ehlermann, La Haya, Kluwer Law International, 2011, p. 423.

63 Art. 17 ESD. Las facultades del art. 13 del ESD no se aplican, por tanto, al Órgano de Apelación. Véase KuYPer, P. J., "The Appellate Body and the Facts», en BroncKers, M. y Quick R. (eds.), New Directions in International Economic Law, Essays in Honour of John H. Jackson, La Haya, Kluwer Law International, 2000, p. 312. Sin embargo, el Órgano de Apelación puede analizar si el Grupo Especial ha valorado objetivamente los hechos, ya que esto constituye una cuestión de derecho: véase Hormonas, op. cit., nota 12, informe del Órgano de Apelación, párr. 132. 
morias aportadas por los amici curie tienen poco impacto en la valoración final ${ }^{64}$. Como ya afirmara el Órgano de Apelación en el asunto Camarones, los Grupos Especiales no están obligados ni a aceptar ni a valorar dicha prueba ${ }^{65}$. En Productos Biotecnológicos, un asunto donde la prueba científica y la incertidumbre en torno a ella eran esenciales para resolver el caso, el Grupo Especial decidió aceptar cinco memorias de amici curie, tres provenientes de universidades y dos de ONG. Sus contenidos, especialmente los concernientes a la prueba científica, no fueron valorados en el informe final con lo que es más que dudosa su influencia en la decisión tomada.

\subsection{4. ¿Pueden las convicciones de un experto hacia el principio de precaución afectar su independencia e imparcialidad?}

Los expertos pueden introducir prueba científica por diversos medios, sea como testigos, peritos, o miembros de comisiones de organismos internacionales. Aun cuando hayan sido propuestos por una de las partes deben actuar ante el panel o tribunal siempre en su propia capacidad y garantizar su independencia $^{66}$. Sin embargo, esto no impide que, fruto de su vida profesional, experiencia y propias convicciones, los expertos tengan su propia concepción sobre cómo abordar determinados problemas o riesgos. Algunos tendrán un curriculum claramente más propenso a utilizar y aplicar aproximaciones precautorias que otros. Como afirma Jacqueline Peel, quienes reciben las opiniones de los expertos pueden no distinguir qué parte de sus evaluaciones son realmente objetivas y cuales están influenciadas por sus convicciones personales, en muchos supuestos precautorias o anti-precautorias ${ }^{67}$. Estas convicciones incluso quedan reflejadas en los informes, por ejemplo, cuando el Dr. Henderson en el asunto Amianto afirmó que el principio de precaución es un complemento importante para la toma de decisiones si no es posible basarse en datos científicos ${ }^{68}$. O el Dr. Frazier en Camarones cuando dijo que la ausencia de información no probaba que no existía un daño ${ }^{69}$. También el Dr. Andow en Productos Biotecnológicos aseguró desconfiar de la opinión mayoritaria de los entomologistas: cada vez que estos eran preguntados sobre los efectos de un nuevo insecticida consideraban que no se crearían resistencias, pero a la larga sí que se producían ${ }^{70}$.

\footnotetext{
${ }^{64}$ Para un análisis general: véase Zambelli, M. «L'amius curiae dans le règlement des différends de l'OMC: Etat des lieux et perspectives», RIDI, 2005, núm. 2, pp. 197-218.

65 Camarones, op. cit., nota 12, informe del Órgano de Apelación, párrs. 104, 108-109.

66 Por ejemplo, el art. 15 del Reglamento del TIDM obliga a los expertos a realizar una declaración solemne sobre su imparcialidad. La declaración es similar incluso para los expertos de parte (de naturaleza testimonial). Véase art. 79.b) del mismo Reglamento.

67 PeEL, J., The precautionary principle in practice: Environmental decision-making and scientific uncertainty, Sidney, Federation Press, 2005, p. 157.

68 Amianto, op. cit., nota 12, informe del Grupo Especial, párr. 5.624.

${ }^{69}$ Camarones, op. cit., nota 12, informe del Grupo Especial, párr. 5.273. Esta idea será luego invocada en Productos Biotecnológicos, op. cit., nota 12, párr. 7.269.

70 Productos Biotecnologicos, ibid., Anexo H, párr. 39.
} 
No parece que las convicciones en cuanto al principio de precaución, o su intensidad, deban impedir la incorporación de un experto. Sí que puede que dichos elementos deban ser tenidos en cuenta a la hora de valorar la prueba por estos aportada. Al final, la independencia e imparcialidad no son cualidades personales de los expertos sino más bien el resultado de un sistema procesal contradictorio destinado a desacreditar a aquellos expertos que no puedan demostrar tales cualidades ${ }^{71}$. Sin embargo, no puede negarse que dicha impronta precautoria puede marcar mucho la decisión final del tribunal internacional, como ocurrió en Atún de aleta azul donde la clara inspiración precautoria de los informes del Prof. Beddington contribuyó a que se reconociese la necesidad de incluir una gestión precautoria de los stocks de atún ${ }^{72}$.

\subsection{La distinción entre elementos fácticos y jurídicos}

La justicia internacional sigue el principio da mihi factum, dabo tibi ius que obliga a separar claramente hechos y derecho. Por ello, la prueba científica, introducida en el proceso esencialmente a través de los expertos, no debería contener valoraciones jurídicas ${ }^{73}$ y menos aun el tribunal debería preguntar cuestiones que impliquen tomar decisiones a favor de una $\mathrm{u}$ otra parte, ya que de ese modo se podría estar contaminando el proceso. No obstante, en los casos complejos, donde se aplica el principio de precaución, muchas veces resulta muy difícil hacer esta separación. Así, al aportar la prueba científica los expertos pueden llegar a valorar, e incluso ser preguntados, sobre la necesidad o razonabilidad de las medidas precautorias adoptadas, siempre de acuerdo con su conocimiento del estado de la ciencia, aunque ello no deje de constituir opiniones que mezclan elementos fácticos con conceptos jurídicos muchas veces indeterminados ${ }^{74}$.

El Derecho OMC contiene numerosos ejemplos de conceptos que permiten estas interconexiones. Así los test de necesidad del art. XX.b) del GATT y del art. 2.2 del Acuerdo MSF, la prohibición de distinciones arbitrarias o injustificadas del art. 5.5 del Acuerdo MSF, o el concepto jurídico indeterminado de evaluación de riesgos presente, entre otros, en la cláusula precautoria del art. 5.7 del Acuerdo MSF, son terreno abonado para que los Grupos Especiales no solo se informen sino que a veces trasladen la valoración de la prueba a los propios expertos. Por ejemplo, en el asunto Amianto se preguntó a los expertos sobre si las medidas comunitarias que prohibían la comercialización de los productos implicados eran necesarias para proteger la vida

71 Gambardella, op. cit., nota 47, p. 149.

72 Polacheck, T. y Preece, A., "A scientific overview on the status of the southern Bluefin tuna stocks», estudio incluido como Anexo 4 por Australia (véase Atún de aleta azul, op. cit., nota 13).

73 Plantas de Celulosa, op. cit., nota 11, voto particular del Juez Cançado Trindade, párrs. 70 y 71.

74 Según Jean Salmon en Derecho internacional la interpretación de estos conceptos no necesariamente precede su aplicación sino que hay una dinámica dialéctica entre los dos procesos: véase Salmon, J. J. A., "Le fait dans l'application du droit international», Recueil des Cours, vol. 175, 1982, pp. 257-414. 
o la salud humana en el contexto del art. XX.b) del GATT (un concepto con relevancia jurídica) y en particular si existían otras medidas menos restrictivas, lo que ahonda aun más en la valoración del concepto ${ }^{75}$. Asimismo, en el contencioso Productos Biotecnológicos se incluyó en el cuestionario por escrito una pregunta sobre si la prueba aportada por las partes era suficiente para adoptar medidas provisionales en base al art. 5.7 del Acuerdo MSF $^{76}$ y si realmente el estado del arte no permitía realizar una evaluación de riesgos definitiva ${ }^{77}$.

Según Vern Walker la clave estaría en la distinción entre lo general y lo particular del caso. Un tribunal puede preguntar a un experto sobre qué medidas son necesarias, razonables, proporcionadas o suficientes para realizar una evaluación de riesgos o adoptar una medida precautoria, pero lo que no puede hacer es pedir que valoren, en concreto, la prueba aportada por las partes y emitan un juicio al respecto. Es más, estos juicios no solo incidirían en el caso concreto sino que al hacerlos propios el tribunal o panel pueden tener la fuerza del precedente para casos futuros ${ }^{78}$.

Un ejemplo de cómo se puede corregir esta mala práctica lo encontramos en el asunto Hormonas. La clave de este caso era dilucidar si la información científica disponible (sobre los efectos dañinos para la salud de ingerir carnes provenientes de animales que habían recibido hormonas para acelerar su crecimiento) era o no insuficiente, de modo que se pudiese utilizar el art. 5.7 del Acuerdo MSF. Las CE preguntaron a varios expertos, directamente, sobre si la información era insuficiente y los Estados Unidos objetaron afirmando que este era un concepto jurídico y no fáctico. La pregunta tuvo que volver a redactarse en el sentido de si la información que las CE habían puesto a disposición para justificar su conclusión era o no suficiente para realizar una evaluación de riesgos lo que, según hemos dicho, no deja de tener cierto contenido valorativo sobre el caso concreto ${ }^{79}$.

En la CIJ la distinción entre hechos y derecho se hace normalmente en la valoración y no en el momento de la producción de la prueba. En el asunto Plantas de Celulosa los votos particulares de los Jueces Al-Kashawneh y Simma, y la declaración del Juez Yusuf, resaltaron la responsabilidad de la Corte en interpretar el Derecho, el encuadramiento jurídico de los hechos y la valoración de la prueba, tarea que no puede recaer en los expertos aunque, el Juez Yusuf, reconoce que sí se le puede preguntar a un experto su opinión sobre

75 Amianto, op. cit., nota 11, informe del Grupo Especial, Anexo VI, Transcripción de la reunión con Expertos, párrs. 381, 383 y 385.

76 Productos Biotecnológicos, op. cit., nota 11, respuestas de los expertos científicos, preguntas 61, $65,68,71,74$ y 77 .

77 Ibid., preguntas 59, 63, 66, 69, 72, 75 y 78 .

78 WALKER, V., "Transforming science into law: Default reasoning in international trade disputes», en Wagner, W. y SteInzor, R. (eds.), Rescuing Science from Politics: Regulation and the distortion of scientific research, Cambridge, Cambridge University Press, 2006, pp. 165-192, p. 185.

${ }^{79}$ Véase Hormonas II, op. cit., nota 12, informe del Grupo Especial, Transcripción de la reunión del Grupo Especial con los expertos (Anexo G), párr. 370. 
"ciertas pruebas en particular» ${ }^{80}$. En el asunto Ballenas, el voto disidente del Juez Owada criticó que en el proceso de cross-examination y re-examination de los testigos-expertos se mezclaron elementos fácticos con jurídicos ${ }^{81}$.

\section{LA CARGA DE LA PRUEBA Y EL PRINCIPIO DE PRECAUCIÓN}

Dado que la incorporación de la prueba, incluso la científica, corre esencialmente a cargo de las partes, la carga de la prueba puede tener un papel muy relevante en la vialidad del caso. Si la parte sobre la que pesa la obligación de probar no demuestra sus alegaciones, puede que el asunto se resuelva sin siquiera analizar el fondo. Los tribunales internacionales siguen el principio actori incumbit probatio ${ }^{82}$, aunque a diferencia del Derecho nacional, no lo suelen incluir en sus normas procesales ${ }^{83}$, lo que permite cierta flexibilización interpretativa.

Si bien actori incumbit probatio, es un principio consolidado y reiteradamente mencionado en la jurisprudencia ${ }^{84}$, sin embargo, no es un principio rígido y la intensidad probatoria exigida puede variar según el contexto. No es lo mismo quien alega una regla general que el que pretende aplicar una excepción, y existen criterios especiales para evitar la llamada prueba negativa o diabólica. En tales casos una prueba mínima (prima facie) puede ser suficiente para dar por cumplido el requisito ${ }^{85} \mathrm{o}$ inclusive se pueden utilizar indicios o presunciones ${ }^{86}$.

¿Puede el principio de precaución afectar la carga de la prueba? Primero debemos recordar, tal como se mencionó en la introducción, que el principio de precaución es claramente una forma de revertir la carga de la prueba administrativa (es decir, la que imponen las autoridades —o se imponen sobre

80 Plantas de Celulosa, op. cit., nota 11, voto particular de los Jueces Al-Khasawneh y Simma, párr. 16; declaración del Juez Yusuf, párrs. 10-12.

${ }^{81}$ Ballenas, op. cit. , nota 11, voto particular del Juez Owada, párrs. 24-25. De modo similar los votos particulares de los Jueces Abraham (párr. 36), Yusuf (párr. 44), Xue (párr. 15) y Sebutinde (párr. 9).

82 ShabTaI, R., The law and practice of the International Court 1920-2015, Brill, 2015, p. 1040; KAZAZI, M., Burden of Proof and Related Issues: A Study on Evidence Before International Tribunals, La Haya, Martinus Nijhoff Publishers, 1996, p. 54; y PAUwElYN, J., «Evidence, proof and persuasion in WTO dispute settlement. Who bears the burden?», Journal of International Economic Law, vol. 1, 1998, pp. 227-258, pp. 235-237.

${ }^{83}$ No lo incluyen ni la CIJ, ni el TIDM, ni el OSD de la OMC. Como cita Foster, su incorporación fue discutida en el informe especial sobre procedimiento arbitral de 1950 de la Comisión de Derecho Internacional pero finalmente no se incluyó en las reglas modelo de 1958. Solo el art. 24 de las reglas opcionales sobre arbitraje de la Corte Permanente de Arbitraje lo incluye, así como el art. 24 de las de Comisión de las Naciones Unidas para el Derecho Mercantil Internacional: véase FosTER, C. E., op. cit., nota 17 , p. 194.

${ }^{84}$ Por ejemplo, Plantas de Celulosa, op. cit., nota 11, párr. 162.

85 KAZAZI, M., op. cit., nota 82, pp. 332-40. AMERASINGHE, C. F., Evidence in International Litigation, La Haya, Martinus Nijgoff, 2005, p. 249. En el Derecho OMC el uso de la prueba prima facie como desencadenante de una inversión de la carga de la prueba es ampliamente utilizada, incluso ante supuestos en donde la prueba no es de difícil producción. Véase, entre otros, Hormonas, op. cit., nota 12, informe de Órgano de Apelación, párr. 104.

${ }^{86}$ Foster, C. E., op. cit., nota 17, p. 234. 
ellas- en el contexto de una medida precautoria) pero no necesariamente la procesal que estamos analizando en esta sección. La diferencia se hizo clara en el asunto Productos agrícolas, donde la carga de la prueba impuesta por Japón para que todo Estado exportador demostrase que su tratamiento fitosanitario sobre la variedad exportada alcanzaba los niveles exigidos (carga de la prueba administrativa) no era lo mismo que el que pesaba sobre Estados Unidos para demostrar que la medida contravenía el Acuerdo MSF (carga de la prueba procesal ${ }^{87}$.

Hasta el momento el principio de precaución no ha sido interpretado por la jurisprudencia internacional como un mecanismo que implique la reversión de la carga de la prueba en los procedimientos internacionales. Así, en el asunto Planta MOX se rechazó el argumento de Irlanda que solicitaba, con arreglo al principio de precaución, que se le impusiese a Reino Unido la obligación de demostrar que las actividades propuestas no provocarían daño alguno. Igualmente en Pruebas Nucleares II se rechazó un argumento similar de Nueva Zelanda.

Sin embargo, parece que el argumento comienza a aparecer en votos particulares, por ejemplo, en los del Juez Laing en las medidas provisionales de Atún de aleta azul ${ }^{88}$, del Árbitro Griffith en Planta $M O X^{89}$ y el del Juez Weeramantry en el Pruebas Nucleares II. Este último afirmó:

"There are two ways of approaching this question. The first is to place the burden of proof fairly and squarely upon New Zealand, and to ask whether a prima facie case has been made out of the presence of such dangers as New Zealand complains of.

The Second approach is to apply the principle of environmental law under which, where environmental damage of any sort of threatened, the burden of proving that it will not produce the damaging consequences complained of is placed upon the author of that damage. In the is view of the mater, the Court would hold that the environmental damage New Zealand complains of is prima facie established in the absence of proof by France that the proposed nuclear test are environmentally safe ${ }^{90}$.

Estos votos defendieron la posibilidad de que el principio de precaución, en casos medioambientales, pudiese revertir el principio actori incumbit probatio una vez demostrada la gravedad del daño hipotético (en dos de los casos incuestionable al tratarse de riesgo nuclear) y sin necesidad de demostrar ni la probabilidad de ocurrencia ni la incertidumbre científica. Sin embargo, no se trata de una interpretación extendida.

Aun cuando descartásemos una reversión total, sí que pueden inferirse ciertos efectos sobre la carga de la prueba inspirados en el principio de precaución. Recordemos que según la definición dada en la introducción, el

87 Productos agrícolas, op. cit., nota 12, informe del Grupo Especial, párr. 8.13.

88 Atún de aleta azul, op. cit., nota 13, voto particular del Juez Laing, párrs. 1.4 y 21.

89 Planta MOX, op. cit., nota 13, voto particular del Árbitro Griffith, párr. 72.

90 Pruebas Nucleares II, op. cit., nota 11, voto particular del Juez Weeramantry, p. 48. 
principio de precaución actúa en contextos de falta de certeza científica y de peligro de daño grave e irreversible ${ }^{91}$. Ambos supuestos, como vimos en la subsección anterior, implican necesariamente prueba científica muchas veces de difícil producción. Razones de correcta administración de justicia pueden llevar a reducir las exigencias probatorias, facilitando la aceptación de una prueba preliminar, prima facie, o de baja intensidad que, en la práctica, significaría una suerte de moderación ${ }^{92}$ de la carga probatoria fundada en el principio de precaución.

Un grupo de casos en donde puede inferirse ese efecto tiene que ver con las medidas provisionales o cautelares. Tradicionalmente estas medidas son de difícil admisión. Los tribunales internacionales las consideran excepcionales, y hacen recaer sobre la parte que la solicita una carga de la prueba de gran intensidad sobre el fumus boni iuris y el periculum in mora. En los supuestos donde hay incertidumbre científica, sin embargo, parece que la intensidad de la carga de la prueba se reduce. En Atún de aleta azul se obligó a Japón a volver al nivel de capturas previas al inicio del programa experimental de 1999 cuando existían serias dudas sobre la causa de la reducción del número de ejemplares ${ }^{93}$. Más interesante es el caso de la Planta MOX, donde el TIDM, al negar las medidas provisionales solicitadas por Irlanda, no se basó en la falta de capacidad probatoria por parte del solicitante sino más bien en la suficiente defensa de Reino Unido, que habría logrado demostrar que el riesgo era bajo ${ }^{94}$. Irlanda había alegado el principio de precaución como un factor que invertiría la carga de la prueba y obligaría a Reino Unido a probar la no necesidad de la medida. Según los votos particulares de los Jueces Treves y Wolfrum el tribunal parece no haber seguido esta interpretación, pero el principio de precaución sí que habría reducido sobremanera la carga probatoria de Irlanda y habría centrado la atención las defensas de Reino Unido ${ }^{95}$. En Plantas de Celulosa, las medidas provisionales fueron denegadas porque el riesgo no se consideró inminente (las plantas no habían entrado en operación aún). En este último el principio de precaución parece haber tenido menos afectación que en los demás. En conclusión, siguiendo a Patricia Birnie, Alan Boyle y Catherine Redgwell, parece que las medidas provisionales fueron concedidas en Atún de aleta azul porque los solicitantes demostraron el riesgo, y denegadas en Planta MOX y Plantas de Celulosa porque no lo lograron ${ }^{96}$. Probado prima facie el riesgo, el principio de precaución ayudaría a reducir significativamente la obligación de demostrar el fumus bonis iuris que, en este caso, sería la fundamentación científica sobre la probabilidad de producción. Volveremos sobre la aproximación precautoria utilizando la técnica de la prueba prima facie al tratar el estándar de revisión.

91 Véase nota 2.

92 Foster, C. E., op. cit., nota 17, p. 259.

93 Atún de aleta azul, op. cit., nota 13, párrs. 79-80.

${ }_{94}$ Planta MOX, op. cit., nota 13, párrs. 71-72.

95 Ibid., el voto particular del Juez Wolfrum, párr. 5 y del Juez Treves, párr. 8.

96 Birnie, P., Boyle, A. y Redgwell, C., International Law and the Environment, Oxford, Oxford University Press, 2009, p. 158. 
También es necesario analizar si las facultades de los tribunales internacionales para encargar sus propios medios probatorios no pueden alterar la obligación de una de las partes según las reglas de la carga de la prueba. Por ejemplo, en Productos agrícolas el Grupo Especial fundó su decisión condenatoria contra Japón no en una prueba aportada por Estados Unidos sino más bien en los informes encargados a un experto independiente. Al llegar el caso al Órgano de Apelación se aclaró que si bien los árbitros tienen gran capacidad para investigar los hechos no pueden usar dicho poder para beneficiar a una de las partes cuando esta ni siquiera ha demostrado, prima facie, sus argumentos ${ }^{97}$.

Aunque a iniciativa del propio tribunal, diferente es el caso en que se suspende el procedimiento, normalmente a través de una medida provisional o cautelar basada en el principio de precaución, y se promueve a que las partes intenten llegar a un acuerdo sobre los aspectos técnicos del conflicto. Los desenlaces, sin embargo, son dispares. En Malasia c. Singapur el TIDM fijó unas medidas provisionales requiriendo a las partes abrir consultas para establecer un grupo de expertos con el mandato de dirigir un estudio que determinase, en el plazo de un año, los efectos de las obras iniciadas por Singapur para ganar territorio al mar y propusiese medidas para mitigar sus efectos negativos ${ }^{98}$. Un año después las partes presentaron el informe conjunto y un acuerdo que resolvía la disputa. El tribunal emitió laudo siguiendo esta solución sin necesidad de vista ${ }^{99}$. El mismo tribunal, en el asunto Atún de aleta azul, emitió otra medida cautelar ${ }^{100}$ fundada en la necesidad urgente de preservar la población de atunes. Dicha medida requería a las partes que iniciasen negociaciones para determinar de forma cooperativa el método de cálculo de la población de atunes, particularmente la edad de maduración, la mortalidad natural, la probabilidad de ser pescados y la densidad en las áreas actualmente en veda. A pesar de que el Tribunal requirió el estudio conjunto en el plazo de algunas semanas no se llegó a un acuerdo entre las partes ${ }^{101}$. En definitiva, en los casos en que las partes llegan a un acuerdo no se alteraría la carga de la prueba. Aquí el principio de precaución ayudaría a resolver, en todo o en parte, el conflicto.

Finalmente una mención al asunto Ballenas. En este caso, si bien el principio de precaución se trata de forma incidental, la CIJ parece haber aplicado una suerte de inversión de la carga de la prueba ya que hizo recaer todo el peso sobre Japón. Sin embargo, esto se debería más bien al carácter de excep-

97 Sin embargo, esta opinión en contrario no alteró el fondo del caso, ya que el informe independiente fue aceptado por ambas partes. Véase Productos agrícolas, op. cit., nota 12, informe del Órgano de Apelación, párrs. 129-130. Para un comentario, Pauwelyn, J., op. cit., nota 55, p. 354. El mismo criterio se siguió posteriormente en Amianto, op. cit., nota 12, párr. 8.81, en donde se cita el informe anterior.

98 Malasia c. Singapur, op. cit., nota 13, párr. 106.1.a.i).

99 Ibid.

100 Atún de aleta azul, op. cit., nota 13, párr. 90.

101 Para un análisis del caso, véase Foster, C., «The "real dispute" in the Southern Bluefin Tuna case: A scientific dispute?», International Journal of Marine and Coastal Law, vol. 16, 2001, núm. 4, pp. 571-601. 
JUSTO CORTI VARELA

ción del art. VIII del Convenio Internacional para la regulación de la pesca de la ballena ${ }^{102}$ (ICRW) que al principio de precaución.

\section{EL PRINCIPIO DE PRECAUCIÓN Y EL STANDARD OF REVIEW}

Como mencionamos en la introducción, el principio de precaución está incluido en diversos tratados internacionales. En los textos medioambientales suele ser una inspiración para que los Estados desarrollen una normativa interna o alcancen acuerdos internacionales proclives a la actuación ante una situación de riesgo grave e incertidumbre científica ${ }^{103}$. En otros casos, actúa más bien como excepción o justificación ante el incumplimiento de obligaciones internacionales, como las del libre comercio ${ }^{104}$. En esta sección no se realizará un análisis de los textos legales sino más bien de la valoración que ha tenido la jurisprudencia sobre ellos. En especial intentaremos definir, en la medida de lo posible, los estándares de revisión que se han llevado a cabo en uno y otro supuesto.

\subsection{El principio de precaución como atenuante}

$\mathrm{Al}$ abordar la carga de la prueba, en la sección anterior, realizamos una distinción entre carga de la prueba procesal y administrativa. No hay duda que el principio de precaución revierte la carga de la prueba administrativa, reduciendo la obligación de justificación por parte de los Estados para adoptar una medida precautoria. Como vimos esto no necesariamente se traslada al proceso judicial o arbitral pero sí que es verdad que tiene una influencia en el estándar de revisión, especialmente si se trata de una medida estatal que pretende ser reconocida como excepción a un principio de Derecho internacional, por ejemplo, el libre comercio. El principio de precaución actuaría como amplificador de la discrecionalidad de los Estados en la adopción de medidas restrictivas y, por tanto, reduciría el estándar de revisión por parte de los tribunales internacionales. La jurisprudencia de la OMC ofrece un conjunto interesante de ejemplos al respecto.

El primer mecanismo de atenuación sería el recurso de la prueba mínima o prima facie. Este no altera la carga de la prueba pero reduce significativamente su peso cuando el demandante dispone a su favor el principio de

102 "Notwithstanding anything contained in this Convention any Contracting Government may grant to any of its nationals a special permit authorizing that national to kill, take and treat whales for purposes of scientific research subject to such restrictions as to number and subject to such other conditions as the Contracting Government thinks fit, and the killing, taking, and treating of whales in accordance with the provisions of this Article shall be exempt from the operation of this Convention. Each Contracting Government shall report at once to the Commission all such authorizations which it has granted. Each Contracting Government may at any time revoke any such special permit which it has granted».

103 Véase nota 2.

104 Por ejemplo, el art. XX.b) del GATT o el art. 5.7 del Acuerdo MSF. 
precaución ${ }^{105}$. No queda claro cuánto ni cómo se cumple este requisito, pero lo que si parece es que puede usarse tanto como una reversión de la carga de la prueba (como vimos en la sección 3) o como un nivel mínimo de prueba necesario para entrar a valorar el fondo ${ }^{106}$.

En segundo lugar, al revisar las evaluaciones de riesgos que fundan medidas precautorias los Grupos Especiales no deben buscar la verdad científica sino más bien un punto intermedio entre esta y la mera verificación del cumplimiento de los procedimientos ${ }^{107}$. En el asunto Hormonas, el Órgano de Apelación afirmó que el Grupo Especial no debe realizar un reexamen ex novo de la evaluación de riesgos realizada por los Estados, ni tampoco tener una deferencia total, limitándose a comprobar los pasos procesales. Lo que debe hacer es una «evaluación objetiva de los hechos» ${ }^{108}$. Más tarde, en Hormonas II, el Órgano de Apelación vuelve a criticar la valoración realizada por el Grupo Especial. Este había realizado una valoración minuciosa de cada prueba científica aportada para tratar de dilucidar la toxicidad del estradiol. Para el Órgano de Apelación el Grupo Especial había excedido el mandato del art. 13 del ESD de realizar una evaluación objetiva de los hechos, ya que este se cumpliría dilucidando si la evaluación de riesgos realizada por la $\mathrm{CE}$ se correspondía o no con el estado de los conocimientos científicos, debiendo ser esta coherente y estar justificada con objetividad ${ }^{109}$.

Finalmente, se reconoce un amplio margen de maniobra a los Estados para declarar una situación de ausencia de pruebas científicas suficientes (elemento necesario para adoptar medidas precautorias). Según la jurisprudencia de la OMC un Estado puede discrepar con los postulados de una organización científica internacional que considera que sí había información suficiente y, por tanto, no había que aplicar medidas precautorias. Incluso dijo que la suficiencia o insuficiencia no es una cuestión de «masa crítica» de información científica. En algunos supuestos la cantidad de estudios (especialmente cuando hay una evolución lenta) puede ser determinante pero en otros una sola investigación que cree un cambio de paradigma puede ser suficiente ${ }^{110}$.

Como puede apreciarse el principio de precaución refuerza la capacidad de los Estados para tomar decisiones de excepción. El control que realiza la jurisprudencia es relativamente laxo, para evitar excesos o violaciones al principio de no discriminación, pero no entra a valorar la verdad científica de la decisión. Esto es así porque en estos casos el principio de precaución se ve reforzado por el principio de soberanía, en especial el de determinar el

105 PeEL, J., op. cit., nota 67, p. 155, y Fisher, E., op. cit., nota 9, p. 331.

106 Devaney, J., op. cit., nota 28, pp. 144-146, y Barceló, J., «Burden of Proof, Prima Facie Case and Presumption in WTO Dispute Settlement», Cornell International Law Journal, vol. 42, 2009, núm. 23, p. 26.

107 Truilhé-Marengo, E., op. cit., nota 60, p. 173.

108 Art. II ESD, Hormonas, op. cit., nota 12, informe del Órgano de Apelación, párr. 117.

109 Hormonas II, op. cit., nota 12, informe del Órgano de Apelación, párrs. 590, 612-615.

110 Ibid., párr. 591. 
nivel de riesgo aceptable. Este derecho está reconocido en el Acuerdo MSF (art. 3.3) y es una contrapartida a la obligación de fundar sus decisiones en datos científicos (arts. 2.2 y 5.1). El principio de precaución reduciría la intensidad de dicha fundamentación científica.

\subsection{El incumplimiento de obligaciones precautorias internacionales}

Cuando, en cambio, lo que se juzga es una acción estatal que supuestamente viola el principio de precaución, el standard of review es diferente.

Aquí el principio de precaución no sustenta una excepción sino que es más bien la regla a cumplir frente a una medida nacional (no precautoria) que se apoya en el principio de soberanía. A diferencia del caso anterior donde soberanía y precaución iban siempre de la mano ahora los Estados, en ejercicio de esa soberanía, son los que eligen adoptar una visión no precautoria. Es una situación realmente difícil para el tribunal, ya que debe elegir entre un principio consolidado en el Derecho internacional y uno en auge. Lo normal es que intente evitar pronunciarse sobre el fondo ${ }^{111}$ o promueva soluciones amigables ${ }^{112}$ entre las partes. Pero si no tienen más remedio que hacerlo seguramente el estándar de revisión ya no se verá tan influenciado por el principio de precaución.

Esto es precisamente lo que ocurrió en Plantas de Celulosa. En este caso Argentina argumentaba que Uruguay no había cumplido las obligaciones fijadas en el Acuerdo por el que se establece el Estatuto del Río Uruguay, en concreto la de tomar todas las medidas necesarias para preservar el medio acuático y prevenir la contaminación, así como la obligación de proteger la biodiversidad y la riqueza pesquera. Siguiendo los criterios de la sección anterior, hubiera sido suficiente con que Argentina hubiese probado prima facie la incertidumbre y el riesgo para aplicar el principio. Sin embargo, aquí la CIJ cargó sobre Argentina todo el peso de la carga probatoria. El rechazo de las pretensiones de Argentina se basó en que esta no había demostrado que Uruguay había actuado sin la diligencia debida o que las plantas podrían tener efectos dañinos sobre el medioambiente ${ }^{113}$, ni que la alteración de los niveles de oxígeno se debiesen a la proliferación de algas producto de la actividad de las plantas ${ }^{114}$, o que los niveles anormales de nonilfenol ${ }^{115}$ o de dioxinas y furanos ${ }^{116}$ encontrados en el río se debiesen a dicha actividad. No

111 Como ocurrió en Planta MOX (op. cit., nota 13) y en Pruebas Nucleares II (op. cit., nota 11) donde, si bien se invocaron argumentos precautorios, el tribunal no llegó a analizar el fondo del asunto. El primero por haber suspendido el procedimiento a la espera de una decisión del TJUE y el segundo por perderse el objeto al declarar Francia una moratoria sobre sus pruebas nucleares.

112 Como ocurrió en Gabčíkovo (op. cit., nota 11), Atún de aleta azul o Malasia c. Singapur (op. cit., nota 13$)$.

113 Plantas de Celulosa, op. cit., nota 12, párr. 265.

114 Ibid., párrs. 239 y 250.

115 Ibid., párr. 257.

116 Ibid., párr. 259. 
solo recayó en Argentina la carga de la prueba sino que el standard of review fue alto, no admitiendo que la incertidumbre pudiese conllevar aceptar una prueba científica de baja intensidad. Esta interpretación mereció duras críticas, incluso de los miembros del tribunal, que en votos disidentes afirmaron:

"The Court has approached it in a way that will increase doubts in the international legal community whether it, as an institution, is well-placed to tackle complex scientific questions» ${ }^{117}$.

Creemos que no es que la CIJ no haya sabido manejar cuestiones científicas complejas, sino que en el enfrentamiento entre soberanía y precaución se anularon los efectos del segundo sobre el estándar de revisión. Ni siquiera la violación de los procedimientos de los arts. 7 a 12 del Estatuto del Río Uruguay, tal como declaró la CIJ ${ }^{118}$ fueron suficientes para que Argentina pudiera satisfacer a la Corte que parece haberle exigido una prueba científica sustancial y completa.

Ante las críticas recibidas ${ }^{119}$, se esperaba con mucha expectación la decisión en el asunto Ballenas. Los hechos parecían encuadrarlo en la misma categoría. Se trataba de una decisión de un Estado (Japón) que en el marco de un tratado internacional para la protección de las ballenas había adoptado una medida que podía considerarse contraria al principio de precaución ya que pretendía, argumentando la falta de certeza científica sobre su impacto, seguir cazando ballenas con fines de investigación. Aquí el razonamiento de la CIJ cambia y se acerca más al standard of review de la OMC que a los de Plantas de Celulosa, tal como subrayó el Juez Owada en su voto particular ${ }^{120}$. Comienza invirtiendo la carga de la prueba, haciéndola recaer sobre Japón, luego somete la actuación de Japón y en particular sus argumentos científicos a un "objective standard of review» que se desprendería del art. VIII de la ICRW; y finalmente, decide condenar a Japón por considerar que sus actividades, supuestamente con fines de investigación científica, no se basaban en la ciencia. Sin embargo, no siempre llueve a gusto de todos y según el propio Juez Owada la CIJ habría incorporado incorrectamente el standard of review de la OMC, primero porque no dispone de sustento normativo de base y, en segundo lugar, porque parece haber basado su decisión más en la calidad de la ciencia que en los procedimientos seguidos ${ }^{121}$.

A pesar de estas críticas sí que creemos que hay cierta lógica en el razonamiento de la CIJ. En los casos en donde la OMC desarrolló su estándar de revisión de mínima prueba científica el principio de precaución sustentaba la posición del Estado, con lo que habría una justificación para la reducción de la intensidad de la carga probatoria. En cambio en el asunto Ballenas el

117 Ibid., voto disidente de los Jueces Al-Khasawneh y Simma, p. 109.

118 Ibid., párr. 282.

119 Entre otros, Payne, C. R., «Pulp Mills on the River Uruguay (Arg. v. Uru.)», American Journal of International Law, vol. 105, 2011, núm. 94; Juste Ruiz, J. y Bou Franch, V. E., op. cit., nota 5.

120 Ballenas, op. cit., nota 11, voto particular del Juez Owada, párr. 33.

121 Ballenas, ibid., párr. 37. Confrontar con MBEnGue, M. M., op. cit., nota 16, p. 547. 
Estado pretendía escapar al principio de precaución. Es normal que aquí el estándar de revisión tenga que ser más intenso, analizando no solo los procedimientos y la apariencia de sustento científico sino también el propio contenido intrínseco de los argumentos. En definitiva, Japón fue condenado porque no disponía de la mínima prueba para demostrar la calidad científica de su accionar.

\section{CONCLUSIONES}

En los casos complejos, donde la prueba científica está en el centro del conflicto, el principio de precaución puede ser una herramienta interesante para ayudar al juez en su labor. Su aplicación exige previamente constatar la incertidumbre científica y la gravedad del riesgo, dos presupuestos que solo pueden comprobarse a través de una correcta incorporación de la prueba científica. Los mecanismos de incorporación de la prueba científica fundados exclusivamente en la prueba de parte son más propensos a provocar la sensación de contradicción y falta de certeza. En cambio los que promueven las pruebas de oficio puede que reduzcan la aplicación del principio. En cuanto a la carga de la prueba, el desarrollo de la jurisprudencia conduce a que el principio de precaución invierta la carga, no de forma formal pero si material, a través del mecanismo de la prueba mínima o prima facie. Sin embargo, ya hay varios ejemplos donde la reversión es total y automática. Tanto la inversión de la carga de la prueba como los estándares de revisión varían según si el principio se aplica en forma conjunta o enfrentada con el de soberanía. Cuando el principio de precaución beneficia una decisión soberana de un Estado frente a una obligación internacional, la tendencia es la de ampliar sus efectos dentro del proceso. En cambio, cuando hay contradicción, los efectos son mínimos y solo ante casos de ausencia total de justificación científica, normalmente procedimental y no de fondo, se puede llegar a una decisión condenatoria contra el Estado infractor.

En todo el proceso antes descrito puede evidenciarse un cierto diálogo judicial entre los tribunales internacionales. La CIJ, aun sin citarlo expresamente, comienza a tener en cuenta y aplicar criterios más flexibles para la incorporación de la prueba científica, inspirados claramente en la jurisprudencia del OSD. En la carga de la prueba el TIDM parece adoptar la delantera, permitiendo cierta inversión de la carga de la prueba cuando se trata de la aplicación del principio de precaución, lo que está siendo tenido en cuenta por la CIJ (más tibiamente) y también por el OSD. Seguramente en el estándar de revisión y la utilización del mecanismo de prueba prima facie es donde el diálogo entre la CIJ y el OSD ha quedado más en evidencia, con menciones expresas en los votos particulares. A pesar de ello, la ausencia de citas cruzadas nos hace concluir que los avances son tenues. Por ello mismo nos surge la duda de si se trata de un proceso de diálogo judicial o simple evolución paralela. En cualquiera de ambos casos, como ya dijera el Juez Guillaume en el año 2000, el inter-judicial dialogue puede llegar a ser una minimalist solu- 
tion para coordinar la proliferación de órganos judiciales internacionales ${ }^{122}$. Estos tienden a buscar sus propios caminos, lo que constituye un serio riesgo para la coherencia en la aplicación del Derecho internacional que, sin duda, habría que intentar impedir.

\section{RESUMEN}

\section{EL PRINCIPIO DE PRECAUCIÓN EN LA JURISPRUDENCIA INTERNACIONAL}

Pese a que el principio de precaución es esencialmente una herramienta para la toma de decisiones a nivel nacional, consideramos que también puede ser útil como mecanismo procedimental en la resolución de disputas internacionales en un contexto de incertidumbre científica. Este artículo estudia la jurisprudencia de tres instancias internacionales (CIJ, OMC y TIDM) para analizar el proceso de incorporación de la prueba científica, el impacto del principio de precaución sobre la carga de la prueba y su influencia en el estándar de revisión.

Palabras clave: principio de precaución, incorporación prueba científica, carga de la prueba, estándar de revisión, CIJ, OSD/OMC, TIDM.

\section{ABSTRACT \\ THE PRECAUTIONARY PRINCIPLE IN INTERNATIONAL CASE LAW}

Although the precautionary principle is mainly a tool for decision making at national level it could also be useful as a judiciary mechanism in the settlement of international disputes involving scientific uncertainties. In this article we study the case law of three international courts (ICJ, WTO and ITLOS) in order to analyse the fact-finding of scientific evidence, the impact of the precautionary principle over the burden of proof and its influence on the standard of review.

Keywords: precautionary principle, fact-finding of scientific evidence, burden of proof, standard of review, ICJ, DSB/WTO, ITLOS.

122 Guillaume, G., «The proliferation of international judicial bodies: The outlook for the international legal order», discurso del presidente de la CIJ ante la Asamblea General de las Naciones Unidas, 27 de octubre de 2000 . 